\title{
Size of colorectal polyps determines time taken to remove them endoscopically
}

\section{(ㄷ)(1) $\odot$}

\author{
Authors \\ Heechan Kang ${ }^{1}$, Mo Hameed Thoufeeq ${ }^{2}$ \\ Institutions \\ 1 Department of Medicine, Peterborough Hospitals NHS \\ Trust, Peterborough, United Kingdom \\ 2 Sheffield Teaching Hospitals, Sheffield, United Kingdom
}

submitted 3.10.2017

accepted after revision $\quad 2.2 .2018$

Bibliography

DOI https://doi.org/10.1055/a-0587-4681 |

Endoscopy International Open 2018; 06: E610-E615

(c) Georg Thieme Verlag KG Stuttgart · New York

ISSN 2364-3722

Corresponding author

Dr. Mo Hameed Thoufeeq, MBBS, FRCP(UK), Consultant

Gastroenterologist, Lead of Endoscopy, Sheffield Teaching

Hospitals, Sheffield S5 7AU, United Kingdom

Fax: +07921332978

mo.thoufeeq@gmail.com

\section{ABSTRACT}

Background an study aims Polypectomy and endoscopic mucosal resection (EMR) are effective and safe ways of removing polyps from the colon at endoscopy. Guidelines exist for advising the time allocation for diagnostic endoscopy but not for polypectomy and EMR. The aim of this study was to identify if time allocated for polypectomy and EMR at planned therapeutic lists in our endoscopy unit is sufficient for procedures to be carried out. We also wanted to identify factors that might be associated with procedures taking longer than the allocated time and to identify factors that might predict duration of these procedures.

Patients and methods A retrospective case study of planned 100 lower gastrointestinal EMR and polypectomy procedures at colonoscopy and sigmoidoscopy was performed and analyzed with quantitative analysis.

Results The mean actual procedural time (APT) for 100 procedures was 52 minutes and the mean allocated time (AT) was 43.05 minutes. Hence the mean APT was 9 minutes longer than the mean AT. Factors that were significantly associated with procedures taking longer than the allocated time were patient age $(P=0.029)$ and polyp size $(P=$ $0.005)$. Factors that significant changed the actual procedure time were patient age $(P=0.018)$, morphology $(P=$ $0.002)$ and polyp size $(P<0.001)$. Procedures involving flat and lateral spreading tumor (LST) type polyps took longer than the protruding ones. On multivariate analysis, polyp size was the only factor that associated with actual procedure time. Number of polyps, quality of bowel preparation, and distance of polyp from insertion did significantly change procedure duration.

Conclusion Factors that significantly contribute to duration of polypectomy and EMR at lower gastrointestinal endoscopy include patient age and polyp size and morphology on univariate analysis, with polyp size being the factor with a significant association on multivariate analysis. We recommend that endoscopy units take these factors into consideration locally when allocating time for these procedures to be safe and effective.

\section{Introduction}

Colorectal cancer is the third most prevalent cancer in the United Kingdom with 35,000 patients newly diagnosed per annum. There is evidence that resection of adenomatous colonic polyps decreases occurrence of malignancy by up to $90 \%$ [1].

Endoscopic mucosal resection (EMR) has grown in popularity especially when dealing with polyps that are sessile and flat [2]. It involves using "lifting solution" containing intravenous fluids such as saline, dextrose or volume expanders mixed with dyes such as indigo-carmine or methylene blue and adrenaline into the submucosa to raise the polyp; this is followed by resecting the polyp using diathermy [3]. That can be achieved as "en-bloc removal" by removing the polyp in one piece or piecemeal by removing in multiple pieces [4].

Time allocation is essential for smooth running of endoscopy lists and scheduling appointments. With accurate planning of activity, one can improve productivity, efficiency and also monitor the activity done. Patients would also benefit from being informed about how long their procedures are likely to 
take. Procedures taking longer than anticipated has been suggested to be an important factor leading to an inefficient endoscopy service [5].

There are guidelines regarding time allocation for diagnostic endoscopies [6]; a working group of the World Endoscopy Organization suggested time allocation for therapeutic endoscopy in general [7]. However, there are no agreed guidelines for time allocation for therapeutic lower gastrointestinal endoscopy particularly polypectomy and EMR. It is important to allocate sufficient time for these procedures so that they are safely and effectively carried out. This novel study aimed to kick-start the process of assessing the feasibility of the time allocation process for EMR and polypectomy procedures.

We wanted to identify if there any specific factors that determine actual procedure time and any deviation from the allocated time.

\section{Patients and methods}

A retrospective study was carried out over a 6-month period in early 2014. Planned lower gastrointestinal therapeutic procedures (both colonoscopies and flexible sigmoidoscopies) polypectomy and EMR were included. Information pertaining to endoscopy, namely patient demographics, duration of procedure, technique used and polyp characteristics (number, size, and morphology), were obtained from Endobase, our endoscopy reporting system.

Information regarding time allocated units was taken from Anglia Ice, our electronic requesting system, to view the number of units requested for each patient (identified by name, date of birth and hospital number). All procedures were requested by either colorectal surgeons or gastroenterologists. Reasons for referral were mainly need for an expert input or if the referring endoscopist felt that more time was needed at a later time, particularly if there were multiple polyps. The clinicians requesting the procedure were able to request as units with 1 unit calculated as 15 minutes. There were no locally agreed guidelines regarding time allocation; clinicians requested time allocation based on their opinion.

All procedures were done by a single endoscopist. Actual procedure time and allocated time were calculated as time tak- en from time of insertion of the scope into the patient to scope removal.

Polyps were grossly classified based on Paris classification. Polyps were further classified into two categories: polypoid/ protruding and non-polypoid/ non-protruding types. Sessile, sub-pedunculated and pedunculated polyps were included as polypoid/protruding polyps. Flat and lateral spreading tumors were included as non-polypoid/non-protruding polyps.

Planned polypectomy/EMR-related studies that were done over 2 years had a sample size of around 200 cases [8], hence we felt 100 cases would be reasonable for our study, which was done over a 6-month period. All 100 consecutive cases were included. As we included all 100 cases on the dedicated therapeutic lists, we included both EMRs and polypectomies.

Statistical analyses were carried out by an expert statistician using SPSS software. Univariate analyses were carried out using polyp size and morphology and patient age. Morphology-related data (polypoid/non-polypoid) was analyzed using Wilcoxon rank sum test while morphology using Paris classification data was analyzed using Kruskal-Wallis test. Spearman's correlation was used to analyze polyp size. Spearman's correlation was used to analyze procedures with different number of polyps. A multivariate analysis was carried out by using a multivariable regression model.

\section{Results}

One hundred planned therapeutic lower gastrointestinal endoscopies for EMR and polypectomies were analyzed. Mean age of the patients was 66.87 years. Mean polyp size was $24.03 \mathrm{~mm}$. This mirrors studies that suggest that a polyp bigger than $2 \mathrm{~cm}$ is considered to be complex and requiring an expert endoscopist assessment [9]. Twenty-five percent of polyps were removed by piecemeal EMR and the rest were removed by snare polypectomy or en bloc EMR. There were no immediate or delayed complications of the procedures done. Mean actual procedural time (APT) taken was 52 minutes and mean allocated time (AT) was 43.05 minutes. Hence the mean APT was 9 minutes longer than the mean AT ( $\vee$ Table 1 and $\triangleright$ Table 2 ). Forty-four percent of procedures were done within the time allocated. Mean allocated units was 2.87, with 1 unit calculated as 15 minutes.

- Table 1 Patient demographics and actual procedure time.

\begin{tabular}{|c|c|c|c|c|c|c|}
\hline & & $\begin{array}{l}\text { Overall } \\
n=100\end{array}$ & $\begin{array}{l}\text { APT not exceeding AT } \\
44(44.0 \%)\end{array}$ & $\begin{array}{l}\text { APT exceeding AT } \\
56(56.0 \%)\end{array}$ & $P$ value & Method \\
\hline $\begin{array}{l}\text { Units allocated } \\
1 \text { unit }=15 \text { minutes }\end{array}$ & $\begin{array}{l}2 \\
3 \\
4\end{array}$ & $\begin{array}{l}47(47.0 \%) \\
19(19.0 \%) \\
34(34.0 \%)\end{array}$ & $\begin{array}{l}12(25.5 \%) \\
11(57.9 \%) \\
21(61.8 \%)\end{array}$ & $\begin{array}{r}35(74.5 \%) \\
8(42.1 \%) \\
13(38.2 \%)\end{array}$ & 0.002 & C \\
\hline APT & Mean & $51.60 \pm 22.94$ & $34.39 \pm 11.07$ & $65.12 \pm 20.68$ & $<0.001$ & L \\
\hline Age & Mean & $66.87 \pm 11.95$ & $63.77 \pm 15.16$ & $69.30 \pm 7.97$ & 0.029 & L \\
\hline Gender & Male & $\begin{array}{l}50(50.0 \%) \\
50(50.0 \%)\end{array}$ & $\begin{array}{l}24(48.0 \%) \\
20(40.0 \%)\end{array}$ & $\begin{array}{l}26(52.0 \%) \\
30(60.0 \%)\end{array}$ & 0.42 & C \\
\hline
\end{tabular}


- Table 2 Quality of bowel preparation, polyp size, morphology and location and their relevance to actual procedure time.

\begin{tabular}{|c|c|c|c|c|c|c|}
\hline & & $\begin{array}{l}\text { Overall } \\
n=100\end{array}$ & $\begin{array}{l}\text { APT not exceeding AT } \\
44(44.0 \%)\end{array}$ & $\begin{array}{l}\text { APT exceeding AT } \\
56(56.0 \%)\end{array}$ & $P$ value & Method \\
\hline $\begin{array}{l}\text { Quality of bowel } \\
\text { preparation }\end{array}$ & $\begin{array}{l}\text { Inadequate } \\
\text { Adequate } \\
\text { Good }\end{array}$ & $\begin{array}{c}9(9.9 \%) \\
39(42.9 \%) \\
43(47.3 \%)\end{array}$ & $\begin{array}{r}5(55.6 \%) \\
14(35.9 \%) \\
20(46.5 \%)\end{array}$ & $\begin{array}{r}4(44.4 \%) \\
25(64.1 \%) \\
23(53.5 \%)\end{array}$ & 0.48 & $\mathrm{~F}$ \\
\hline Procedure & $\begin{array}{l}\text { Sigmoidoscopy } \\
\text { Colonoscopy }\end{array}$ & $\begin{array}{l}56(56.0 \%) \\
44(44.0 \%)\end{array}$ & $\begin{array}{l}25(44.6 \%) \\
19(43.2 \%)\end{array}$ & $\begin{array}{l}31(55.4 \%) \\
25(56.8 \%)\end{array}$ & 0.88 & C \\
\hline Location code & $\begin{array}{l}1 \\
2 \\
3 \\
4 \\
5 \\
6\end{array}$ & $\begin{array}{c}23(24.5 \%) \\
30(31.9 \%) \\
12(12.8 \%) \\
7(7.4 \%) \\
10(10.6 \%) \\
12(12.8 \%)\end{array}$ & $\begin{array}{r}7(30.4 \%) \\
14(46.7 \%) \\
7(58.3 \%) \\
4(57.1 \%) \\
3(30.0 \%) \\
5(41.7 \%)\end{array}$ & $\begin{array}{r}16(69.6 \%) \\
16(53.3 \%) \\
5(41.7 \%) \\
3(42.9 \%) \\
7(70.0 \%) \\
7(58.3 \%)\end{array}$ & 0.55 & $F$ \\
\hline Morphology & $\begin{array}{l}\text { Sessile } \\
\text { Subpedunculated } \\
\text { Pedunculated } \\
\text { Flat/LST }\end{array}$ & $\begin{array}{c}46(46.0 \%) \\
19(19.0 \%) \\
8(8.0 \%) \\
27(27.0 \%)\end{array}$ & $\begin{array}{c}20(43.5 \%) \\
12(63.2 \%) \\
9(33.3 \%) \\
9(33.3 \%)\end{array}$ & $\begin{array}{r}26(56.5 \%) \\
7(36.8 \%) \\
18(66.7 \%) \\
18(66.7 \%)\end{array}$ & 0.24 & $\mathrm{~F}$ \\
\hline Morphology & $\begin{array}{l}\text { PPP } \\
\text { NPNP }\end{array}$ & $\begin{array}{l}73(73.0 \%) \\
27(27.0 \%)\end{array}$ & $\begin{array}{r}35(47.9 \%) \\
9(33.3 \%)\end{array}$ & $\begin{array}{l}38(52.1 \%) \\
18(66.7 \%)\end{array}$ & 0.19 & C \\
\hline Size(mm) & & $24.03 \pm 17.15$ & $18.18 \pm 11.19$ & $28.71 \pm 19.59$ & 0.005 & $\mathrm{~L}$ \\
\hline
\end{tabular}

Of the procedures booked as 2 units, $25.5 \%$ were done within the allocated time. Of the procedures booked as 3 units and 4 units, $57.9 \%$ and $61.8 \%$, respectively, were done within the allocated time.

Patient age significantly correlated with APT (P: 0.018) ( $\triangleright$ Fig.1). Age was also a strong factor in APT exceeding AT ( $P$ $=0.029)$. Polyp size was a significant factor in APT exceeding AT $(P=0.005)$. Mean polyp size was $18.18 \mathrm{~mm}$ when APT didn't exceed AT. Mean size was $28.71 \mathrm{~mm}$ when APT exceeded AT. There was a significant correlation between time taken and polyp size (mean diameter $=24.03 \mathrm{~mm}, \mathrm{r}=0.57 ; 95 \% \mathrm{Cl}(0.41$, $0.69) P<0.0001$ ) ( $\vee$ Fig. 2). We had details of the size of polyps in all but 1 procedure $(n=99)$.

There was an equal distribution in patient gender (both $n=$ 50); gender made no significant changes to APT. Neither number of polyps in a procedure nor segmental location of them in the colon made APT exceed AT. We had details regarding the exact location of the polyps in 94 procedures.

Having one polyp or more than one polyp made no statistical significance in procedure duration $(n=100$, Spearman $R=$ $-0.134, P=0.18)$.

Procedures with more than one polyp $(n=22)$ were shorter than those with single polyps $(n=78)$ (Mean time: 44.38 minutes vs 53.39 minutes but without reaching statistical significance $(P=0.05)$. By including size of the largest polyps in each procedure with multiple polyps, we obtained a mean polyp size of $15.13 \mathrm{~mm}$. We found no difference in APT if procedures had one or more polyps $(P=0.18)$.

Polyp morphology affected time taken for therapy, with flat/ lateral spreading lesions taking the highest time and sub-pedunculated taking the least $(P=0.02)$. By classifying polyps into

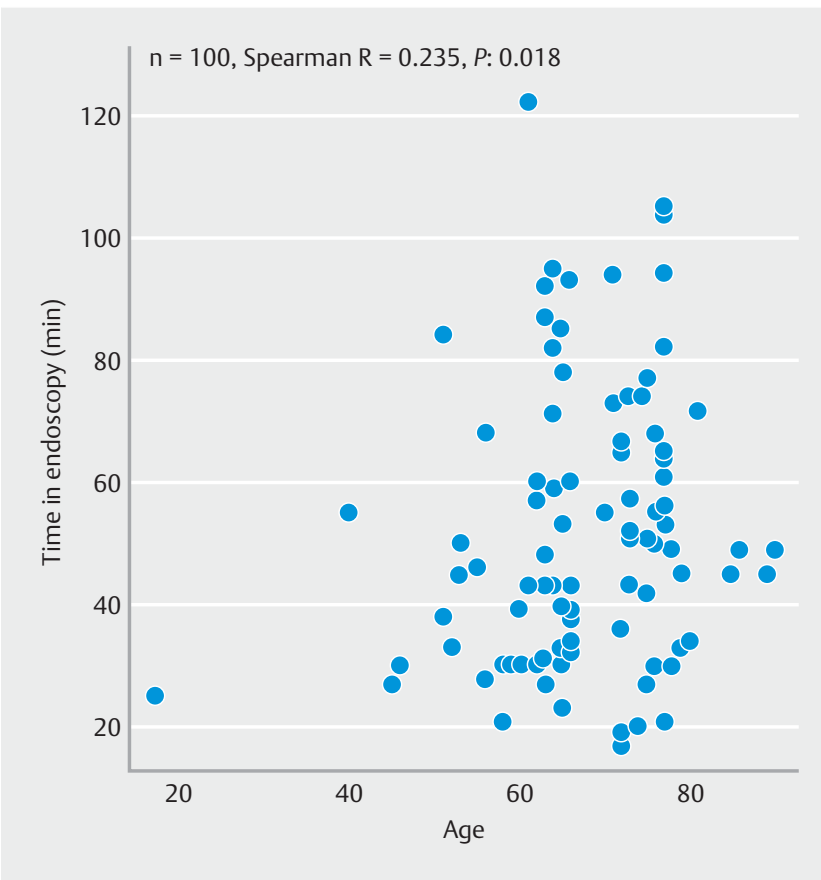

- Fig. 1 Correlation of age and actual procedural time.

non-polypoid and polypoid polyps we noted that there was a significant correlation with APT $(P=0.002)$. Non-polypoid polyps $(n=26)$ took significantly longer than polypoid polyps $(n=64), 66.14$ minutes vs. 47.47 minutes ( $>$ Fig. 3). However, morphology was not a significant factor in APT exceeding AT $(P=0.19)(\triangleright$ Table 2$)$. 


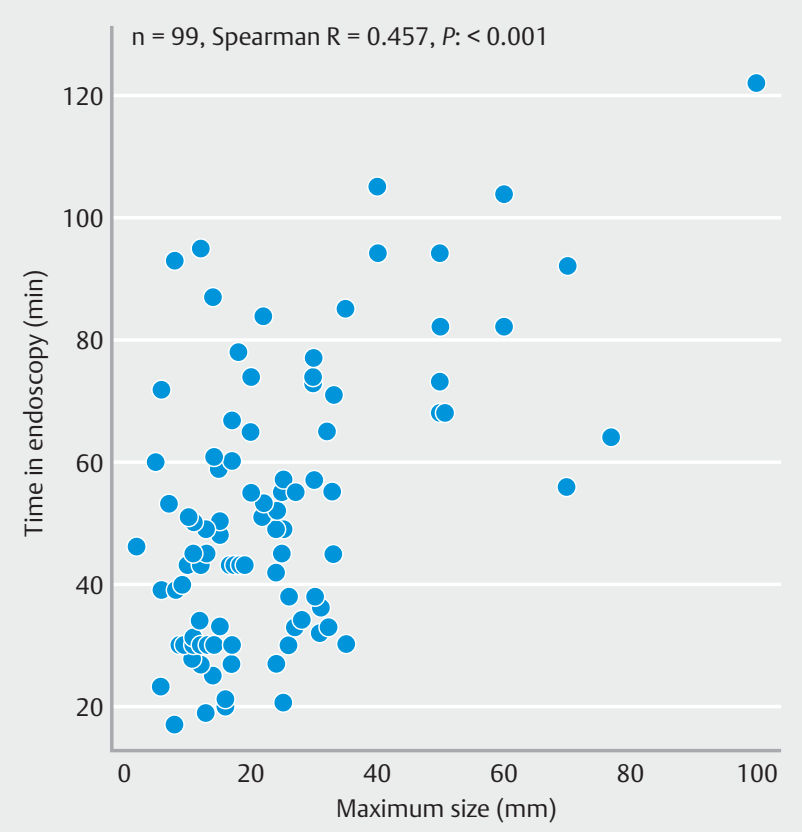

- Fig. 2 Correlation of size of polyp and actual procedural time.

Distance from the scope entry point had no significant impact on APT either left hemi-colon vs. right hemi-colon; 52.33 minutes vs. 51.37 minutes $(P=0.43)$. APT for removing rectal polyps $(n=23)$ vs cecal $(n=12)$ was 64.21 minutes vs. 57.50 minutes $(P=0.20)$. Polyp location in the colon did not significantly change APT $(P=0.25)$. Sigmoidoscopy $(n=56)$ was slightly lengthier than colonoscopy $(n=44)$ (mean times: 53.32 minutes vs 50.24 minutes $(P=0.84)$.

Piecemeal EMR took longer than snare polypectomy $(P=$ $0.001)$. Piecemeal EMRs also were significantly associated with APT exceeding AT compared with snare polypectomy (84\% vs 46.6\%) $(P=0.001)$.

A multivariable regression model ( $\triangleright$ Table 3 ) was built for mean APT using age, morphology, technique and maximum polyp size. Based on that, we found that for every 5-year increase in patient age over the mean there was a 1.25-minute increase in APT. If the polyp was non-polypoid, there was an 8minute increase in APT and if the polyp was $5 \mathrm{~mm}$ over mean size there was a 3.20-minute increase. However, statistical significance was found only for polyp size.

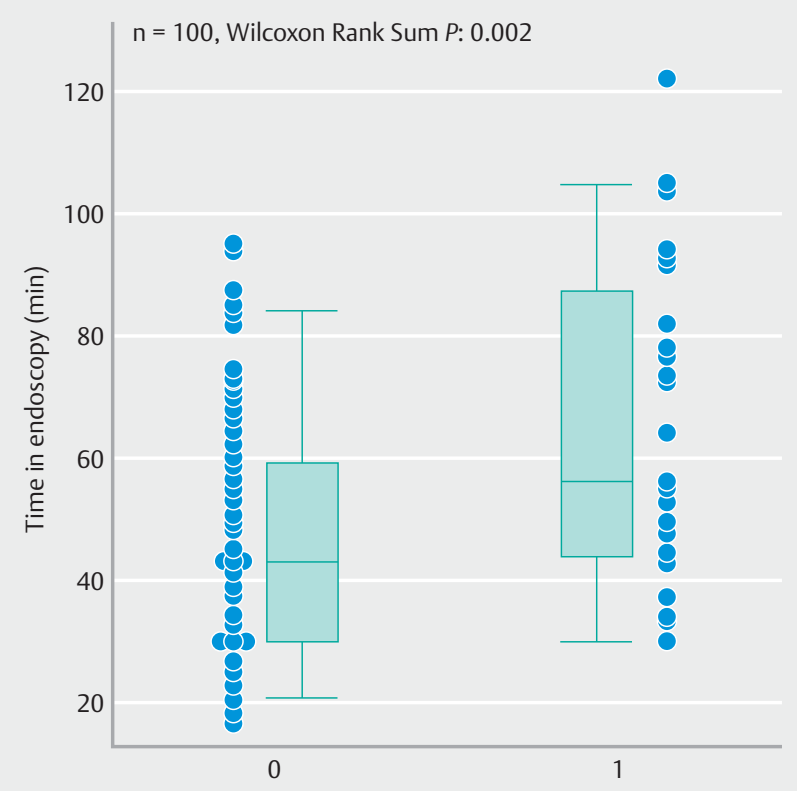

0 Polypoid/protruding polyps

1 Non-polypoid/non-protruding polyps

Fig. 3 Correlation of polyp morphology and actual procedural time.

\section{Discussion}

EMR is a relatively complex endoscopic procedure that is carried out at both secondary and tertiary level centers [10-12]. It is important to allocate sufficient time for it to ensure a good patient experience with endoscopy. Doing so also ensures that polyps are safely and effectively removed. Factors that affected the duration of these procedures were polyp size and morphology. Non-polypoid types such as flat and lateral spreading tumors/lesions required more time compared to polypoid and protruding types, i.e sessile, subpedunculated and pedunculated polyps.

Polyp size had a direct relationship to procedure duration with larger polyps requiring more time. Patient age also significantly affected procedure duration.

The factors that made the actual procedure time exceed the allocated time were patient age and polyp size. Piecemeal EMR also made the procedure time longer than allocated time.

By taking the upper limit of the allocation time for each case and adding them up over the 100 cases, the result is 4,305 minutes. However, the total number of actual minutes over all 100

- Table 3 Multivariable regression model.

\begin{tabular}{|l|l|l|}
\hline Variable & Estimated change in mean ATP (95\%Cl) & P value \\
\hline Age (per 5-year increase) & $1.25(-0.38,2.88)$ & 0.13 \\
\hline Non-protruding/ non-polypoid & $8.24(-1.19,17.6)$ & 0.09 \\
\hline Maximum size (per 5-mm increase) & $3.20(1.92,4.48)$ & $<0.001$ \\
\hline
\end{tabular}


cases was 5,160 minutes. Therefore, the total procedure time exceeded total allocation time (even using upper limits) by 855 minutes (19.9\%), which represents an average of 8.55 minutes over per case. This means that over $50 \%$ of these cases would need a 15-minute higher allocation in order for the average allocation time to be about the same as the average actual time. This supports the general statement that the times are often under-allocated.

Although, the mean ATP was 9 minutes more than AT, the endoscopy team did not feel rushed and carried out all the procedures safely and effectively.

To date, there have been no published guidelines or recommendations pertaining to time allocation for polyp resection. More recently there has been a publication from the British society of gastroenterology regarding polypectomy [13]. They recognized that larger polyps $(>2 \mathrm{~cm})$ and non-pedunculated (sessile and flat) polyps were more complex to remove. However, there was no mention of allocation of time to perform polypectomy. A publication from Germany in 2015 talked about cost allocation for endoscopic procedures, however, no mention of time allocation [14]. Polyp size has previously been found to be an important factor in procedural time for polypectomy [15].

Polyp size has also been found to be associated with higher risk of complications post-polypectomy [16]. Size and morphology are an important part of SMSA score, which predicts outcomes post-polypectomy [17]. Endoscopy units in several nations are remunerated by the nature of the procedures done and it is also important to look at allocated time in detail so that procedures are not only effective and safe but also cost-effective.

Limitations of the study include the limited sample gathered from a single endoscopic unit under a single endoscopist; the endoscopist had extensive experience in EMR and was trained in EMRs having done an endoscopy fellowship in EMR. Although a limitation, consistency in the skill of the endoscopist was preserved, hence there was no variation or operator bias. We also did not take into account the experience of the endoscopy nursing assistants, whose experience in assisting polypectomy and EMRs was variable. We included only procedure time and did not include time taken for patient flow in the department, the pre-endoscopy check or time taken for report writing. There was also a degree of heterogeneity as we included both colonoscopies and sigmoidoscopies. We wanted to match a "typical therapeutic" endoscopy list, which usually has a mixture of procedures. Besides that, we also noted that extent of scope insertion at examination did not significantly affect the time needed for therapy.

\section{Conclusion}

We suggest that endoscopy units take into consideration the factors evaluated in this study when allocating time for endoscopic polyp removal. Endoscopy unit booking offices should ideally work in collaboration with endoscopists to quantify polyp size and morphology prior to allocating time for these procedures. We recommend making available meticulous image documentation of polyps prior to planned resection.

Competing interests

None

References

[1] Winawer S], Zauber AG, Ho MN et al. Prevention of colorectal cancer by colonoscopic polypectomy. The National Polyp Study Workgroup. N Engl J Med 1993; 329: 1977 - 1981

[2] Ferrara F, Luigiano C, Ghersi S et al. Efficacy, safety and outcomes of 'inject and cut' endoscopic mucosal resection for large sessile and flat colorectal polyps. Digestion 2010; 82: 213-220

[3] Mahadeva S, Rembacken B]. Standard "inject and cut" endoscopic mucosal resection technique is practical and effective in the management of superficial colorectal neoplasms. Surg Endosc 2009; 23: $417-422$

[4] Wolff WI, Shinya H. Polypectomy via the fiberoptic colonoscope. Removal of neoplasms beyond reach of the sigmoidoscope. $\mathrm{N}$ Engl J Med 1973; 288: 329-332

[5] Almeida R, Paterson WG, Craig N et al. A patient flow analysis: identification of process inefficiencies and workflow metrics at an ambulatory endoscopy unit. Can J Gastroenterol Hepatol 2016; 2016L: 2574076

[6] Valori H. How many 'points' should there be on an endoscopy list? Joint Advisory Group on gastrointestinal Endoscopy. Available at: https://www.thejag.org.uk/Downloads/Unit\%20Resources/How\% 20many\%20points\%20should\%20there\%20be\%20on\%20an\% 20endoscopy\%20list.pdf

[7] Mulder C], Jacobs MA, Leicester RJ et al. Guidelines for designing a digestive disease endoscopy unit: Report of the World Endoscopy Organization. Dig Endos 2013; 25: 365-375

[8] Swan MP, Bourke M], Alexander $\mathrm{S}$ et al. Large refractory colonic polyps: is it time to change our practice? A prospective study of the clinical and economic impact of a tertiary referral colonic mucosal resection and polypectomy service (with videos) Gastrointest Endosc 2009; 70: $1128-1136$

[9] Ferlitsch M, Moss A, Hassan C et al. Colorectal polypectomy and endoscopic mucosal resection (EMR): European Society of Gastrointestinal Endoscopy (ESGE) Clinical Guideline. Endoscopy 2017; 49: $270-297$

[10] Repici A, Pellicano R, Strangio G. Endoscopic mucosal resection for early colorectal neoplasia: pathologic basis, procedures, and outcomes. Dis Colon Rectum 2009; 52: $1502-1515$

[11] Soetikno RM, Inoue H, Chang KJ. Endoscopic mucosal resection. Current concepts. Gastrointest Endosc Clin N Am 2000; 10: 595-617

[12] Lim TR, Mahesh V, Singh S et al. Endoscopic mucosal resection of colorectal polyps in typical UK hospitals. World J Gastroenterol 2010; 16: $5324-5328$

[13] Rutter MA, Chattree A, Barbour JA et al. British Society of gastroenterology/Association of coloproctologists of Great Britain and Ireland guidelines for the management of large non-pedunculated colo-rectal polyps. Gut 2015; 64: $1847-1873$

[14] Rathmayer M, Scheffer H, Braun M et al. Improvement of cost allocation in gastroenterology by introduction of a novel service catalogue covering the complete spectrum of endoscopic procedures. Z Gastroenterol 2015; 53: $183-198$ 
[15] Moss A, Bourke M, Williams S et al. Endoscopic mucosal resection outcomes and prediction of submucosal cancer from advanced colonic mucosal neoplasia. Gastroenterology 2011; 140: 1909-1918

[16] Rutter M, Nickerson C, Rees C et al. Risk factors for adverse events related to polypectomy in the English Bowel cancer screening programme. Endoscopy 2014; 46: $90-97$
[17] Sansome S, Ragunath K, Bianco MA et al. Clinical utility of the SMSA grading tool for the management of colonic neoplastic lesions. Dig Liver Dis 2017; 49: 518-522 